\title{
Effects of Treatment with Quercetin on the Quality of Cryopreserved Bovine Semen
}

\author{
Stella Maris Teobaldo Tironi, Antonio Campanha Martinez, Flavio Augusto Vicente Seixas, \\ Talitha Fernandes Stefanello, Celso Vataru Nakamura \& Gentil Vanini de Moraes
}

\begin{abstract}
Background: Semen cryopreservation is one of the most common biotechnologies in the reproduction of animals of agricultural interest, especially bulls. However, cryopreservation can be harmful to sperm cells, with susceptibility to oxidative stress being one of the causes. The addition of antioxidants such as quercetin may inhibit and/or reduce such damage, reducing fertility. Quercetin can increasing sperm motility and interaction capacity between spermatozoa-oocyte, to increase cellular metabolism and reduced DNA fragmentation and oxidation following thawing. Therefore, the objective of this study was to evaluate the protective effect of quercetin on the metabolism of bovine semen following thawing. Materials, Methods \& Results: Three Brahman bulls in reproduction age and previously considered fit for reproduction were used. The semen samples were collected via the electroejaculation method, and the samples were homogenized to form pooled semen from three ejaculates, which was diluted in Tris-yolk egg-glicerol diluent medium. Quercetin was added to diluent, to final concentrations of $0,5,10,15$ and $20 \mu \mathrm{g} \cdot \mathrm{mL}^{-1}$ in each group. The samples were kept frozen in straws of $500 \mu \mathrm{L}$, with concentration of $40,000,000$ spermatozoid / $\mathrm{mL}$ for 15 days and were thawed in water at $36^{\circ} \mathrm{C}$ for $30 \mathrm{~s}$. All the tests was performed in five replicates. The cell metabolism status was evaluated by quantification of superoxide radical production with a nitroblue tetrazolium test (NBT) and scanning spectrophotometry. By spermatic evaluation, the following parameters were evaluated via the computerized system of sperm analysis (CASA): total motility (TM, \%), progressive motility (PM, \%), velocity curved line (VCL, $\mu \mathrm{m} / \mathrm{s})$, velocity straight line (VSL, $\mu \mathrm{m} / \mathrm{s})$, velocity average path (VAP, $\mu \mathrm{m} / \mathrm{s}$ ), distance curved line (DCL, $\mu \mathrm{m})$, distance straight line (DSL, $\mu \mathrm{m})$, distance average path (DAP, $\mu \mathrm{m})$, amplitude of lateral head displacement (ALH, $\mu \mathrm{m}$ ), beat cross frequency (BCF, Hz), wobble (WOB = VAP/VCL), linearity (LIN, VSL:VCL) and straightness (STR, VSL:VAP). And by surface analysis through scanning electron microscopy (SEM). The NBT test demonstrated an increase in cell metabolism of approximately $40 \%$ up to the limit of $15 \mu \mathrm{g} \cdot \mathrm{mL}^{-1}$ quercetin. The parameters of CASA pertaining to velocity (VCL, VSL, VAP) and as a consequence, wobble and linearity increased as a function of the quercetin concentration until $20 \mu \mathrm{g} \cdot \mathrm{mL}^{-1}$, which was shown to be statistically significant. No significant morphological changes between groups were observed by the SEM technique.

Discussion: The reduction of NBT indicates oxidative metabolism, being an indirect measure of the oxygen dependent activity of the cells, therefore the results demonstrate that quercetin supplementation increased the number of cells with high metabolic activity. Regarding the evaluation of CASA, according to the literature, some parameters are reliable estimates of the fertilization capacity of the human spermatozoon, among them, the VCL. In this study, all speeds were increased with Quercetin, including LCV, demonstrating its importance in supplementation in bovine seminal diluent. Scanning electron microscopy evaluates the structural morphology of the cell surface. As with previous results, in this study, all cells lost the acrosome. However, this type of damage was already expected in thawed spermatozoa. In addition, no other significant changes were observed in the morphology of the membrane or other parts of the sperm. In general, the results presented here suggest that the addition of quercetin to the seminal diluent before freezing improve spermatic quality, which manifests itself as faster spermatozoa and may higher fertilization rates.
\end{abstract}

Keywords: cryopreservation, oxidative stress, cell metabolism, semen, bulls. 


\section{INTRODUCTION}

Cryopreservation process induces the formation of reactive oxygen species (ROS), which participate in vital processes of spermatozoa under physiological concentrations, such as maturation, capacity building, spermatic hyperactivation, acrosomal reaction and sperm-oocyte fusion [19]. However, under excess concentrations ROS induces oxidative stress that is detrimental to subsequent performance in the functional status of the spermatozoids [24].

Several authors have studied the addition of antioxidants in the seminal diluents in order to improve the sperm quality of cryopreserved semen [20], aiming to inhibit and / or reduce the damage caused by ROS [1], for example the Quercetin.

Quercetin is a flavonoid compound of the polyphenolic group with antioxidant activity at the cell membrane level [18] that is widely found in fruits, vegetables, grains and flowers, as well as in high concentrations in red wine [17].

The literature reports reduction in rates of DNA fragmentation, as well as significant increases in motility and interaction capacity between spermatozoa-oocyte in cryopreserved semen following quercetin treatment [9]. In another study, the addition of quercetin to the seminal diluent increased both sperm motility and cellular metabolism, and also reduced DNA fragmentation and oxidation following thawing [25]. So, the objective of this work was to evaluate whether the antioxidant properties of quercetin could influence the quality of cryopreserved bovine semen.

\section{MATERIALS AND METHODS}

\section{Animals}

Three Brahman bulls aged two and three years were used, which were confined at the Laboratório de Criação e Reprodução Animal of Universidade Estadual de Maringá, Campus Fazenda, in the city of Umuarama, Paraná, Brazil. At this site, the animals received feed based on corn silage, mineral salt and water ad libitum. They underwent andrological examination and were considered fit for reproduction (motility: $<70 \%$, total motility: index 3 , morphological defects: $<30 \%$ and concentration: $350 \times 10^{6}$ spermatozoa/mL), according to CBRA (2013) [2].

Semen collection and sample preparation

The semen samples were collected via the electroejaculation method. Their foreskins were sanitized with lactated ringer solution and a single collection per animal was undertaken. The samples semen were homogenized to form a pooled semen from three ejaculates with a final volume of $2.6 \mathrm{~mL}$ and initial concentration $384,600,000$ spermatozoa $/ \mathrm{mL}$, which was diluted in another $22.4 \mathrm{~mL}$ of diluent medium $(0.2 \mathrm{M}$ Tris, $1 \%$ glucose, $7 \%$ glycerol, egg-yolk $20 \%$, and $\mathrm{pH}$ adjusted to 7.2 with citric acid), to a final volume of $25 \mathrm{~mL}$. The tests were performed in five replicates.

The stock solution of quercetin ${ }^{1}$ was prepared in a diluent medium. The seminal pool was divided into five groups each of $5 \mathrm{~mL}$, denominated $0,5,10,15$ and 20. In group 0 (control), no quercetin was added, whereas in groups 5, 10, 15 and 20, quercetin stock solution was added so that the final concentration corresponded to the quantity of each group as $\mu \mathrm{g} \cdot \mathrm{mL}^{-1}$ unity. The solution from each group was packed into 10 straws of $500 \mu \mathrm{L}$ each, so that the final amount of sperm per straw was approximately 20,000,000 [11].

The straws were gradually cooled. They were initially kept for $4 \mathrm{~h}$ at $4^{\circ} \mathrm{C}$ and then exposed to the vapor of liquid nitrogen for $10 \mathrm{~min}$; finally, they were submerged in liquid nitrogen for storage until the moment of use. The samples were kept frozen for 15 days prior to testing. For each assay performed, the semen samples were thawed via immersion in distilled water at $36^{\circ} \mathrm{C}$ for $30 \mathrm{~s}$ at the time of use.

\section{Cell metabolism assay}

The straws containing semen were thawed and cell metabolism was assessed by quantification of superoxide radical production using the nitroblue-tetrazolium (NBT) ${ }^{1}$ assay, according to the protocol described by Tvrdá et al. [22], with modifications. The NBT salt was dissolved in PBS containing $1.5 \%$ DMSO (dimethyl sulfoxide) ${ }^{2}$ to a final concentration of $1 \mathrm{mg} \cdot \mathrm{mL}^{-1}$, and was added to the cells $(100 \mathrm{~mL}$ per well in an Elisa 96 wells plate). Following a $1 \mathrm{~h}$ incubation (shaker, $37^{\circ} \mathrm{C}, 95 \%$ air atmosphere, $5 \% \mathrm{CO}_{2}$ ), the cells were washed twice with PBS and centrifuged at 300 $g$ for $10 \mathrm{~min}$. Lastly, the cells and formazan crystals were dissolved in $2 \mathrm{M} \mathrm{KOH}^{3}$ in DMSO. Optical density was determined at a wavelength of $620 \mathrm{~nm}$ against 570 $\mathrm{nm}$ as a reference using microcuvettes by a scanning spectrophotometer model $1650 \mathrm{PC}^{4}$. The data were expressed as a percentage of the Control (no quercetin) set to $100 \%$. The NBT test can be used to assess the sequestering ability of the radical $\mathrm{O}_{2}^{-}$, where the change from the pale yellow coloration of the NBT to 
the purple of the formazan is evaluated when reduced [5], that is, the higher the rate of oxidative metabolism, the more active is the cell [16]. The experiments were performed in triplicate.

\section{Scanning Electron Microscopy}

The methodology for performing the Scanning Electron Microscopy followed the protocol described by Grimstone [10] and Dedavid et al. [8], albeit with a decrease in centrifugation speed to $1,200 \mathrm{~g}$ for $5 \mathrm{~min}$ in order to avoid the decapitation of sperm cells. The cells were fixed with a $0.1 \mathrm{M}$ cacodylate buffer and $2.5 \%$ of glutaraldehyde. They were subsequently adhered onto poly-Llysine-coated coverslips, dehydrated in crescent grades of ethanol, critical-point dried with $\mathrm{CO}_{2}$, sputter coated with gold, and observed in a Shimadzu SS-550 scanning electron microscope ${ }^{4}$ at magnifications of $25,000 \mathrm{x}$ in order to evaluate surface structures such as membrane integrity, acrosome presence, tail fixation or absence, presence of cytoplasmic droplets and tail defects.

\section{Computerized sperm analysis system (CASA)}

The semen samples were thawed as described and were immediately analyzed by the Computerized System of Sperm Analysis (CASA) (IVOS II Animal, Hamilton Thorne - Androvision software $)^{5}$. A $3 \mu \mathrm{L}$ sample was placed on each of the glass disposable counting slides. Five straws were analyzed for each group (five slides), five fields for each slide at each treatment condition.

The evaluation of the parameters total motility (TM, \%), progressive motility (PM, \%), velocity curved line (VCL, $\mu \mathrm{m} / \mathrm{s}$ ), velocity straight line (VSL, $\mu \mathrm{m} / \mathrm{s}$ ), velocity average path (VAP, $\mu \mathrm{m} / \mathrm{s}$ ), distance curved line (DCL, $\mu \mathrm{m})$, distance straight line (DSL, $\mu \mathrm{m})$, distance average path (DAP, $\mu \mathrm{m})$, amplitude of lateral head displacement (ALH, $\mu \mathrm{m})$, beat cross frequency $(\mathrm{BCF}, \mathrm{Hz})$, wobble $(\mathrm{WOB}=\mathrm{VAP} / \mathrm{VCL})$, linearity (LIN, VSL:VCL) and straightness (STR, VSL:VAP) were estimated by the Androvision program (Minitube). The statistical analysis of the data was performed by the Tukey test comparing all treatments with a significance level of 5\% $(P>0.05)$ as well as Dunet test, both through the software SAS v.8.

\section{RESULTS}

The results of the metabolic activity evaluated by the NBT test as a function of quercetin treatments are shown in Figure 1.
Results demonstrates that the supplementation of the cryoprotectant solution with quercetin increased the number of cells with high metabolic activity in a significant and concentration-dependent manner.

About investigation of protective effects of quercetin on sperm membrane morphology, Figure 2 shows the morphology of the spermatozoa observed in the different treatments.

It was observed was the failure of the tail and head connection, with a certain degree of fragility in the tail insertion as shown in Figure 2, this being close to a "decapitation" independent of the quercetin concentration used. In all treatments it was observed that some cells lost the acrosome. In addition, no other significant changes were observed in the morphology of the membrane or other parts of the spermatozoid.

In order to compare sperm functionality in each treatment, some parameters were evaluated by CASA system. This table shows a significant improvements in the VCL, VSL and VAP parameters where the last three are related to sperm velocity [23]. Table 1 displays the numerical and statistical quantification for each treatment.

The parameters VCL, VSL, VAP, WOB and LIN increased $(P<0.05)$ as a function of quercetin concentration, but only at the concentration of 20 $\mu \mathrm{g} . \mathrm{mL} 1$, the change was statistically significant. No parameter showed a gradual loss of due to treatment.

\section{DISCUSSION}

The reduction of NBT is directly correlated with the oxidative metabolism, being deemed an indirect measurement of the oxygen-dependent activity of the cells [15]. The literature reports that the free radicals formed during lipid peroxidation can also affect the integrity of cellular proteins in a very significant manner [7], provoking aggregation, fragmentation, amino acid modification, and proteolytic susceptibility [6]. Due to their area and location, the membrane proteins are those that would be most vulnerable to the attack of these radicals, which could cause morphological alterations in this organelle.

Mammalian spermatozoa are very sensitive to damage caused by freezing. This is mainly due to two factors: the absence of cytoplasm, which has as a consequence the absence of an efficient antioxidant defense system [22], and the composition of the cytoplasmic membrane, as susceptibility to low temperatures seems to be linked to a high rate of unsaturated compared to to 
Table 1. Values of motility and sperm kinetic parameters by CASA for each treatment. The column \%, next to the values represents the variation of each parameter compared to control group.

\begin{tabular}{cccccccc}
\hline \multirow{2}{*}{ Treatment/Parameter } & 0 (Control) & \multicolumn{2}{c}{$5 \mathrm{mg} \cdot \mathrm{mL}^{-1}$} & \multicolumn{2}{c}{$15 \mathrm{mg} \cdot \mathrm{mL}^{-1}$} & \multicolumn{2}{c}{$20{\mathrm{mg} \cdot \mathrm{mL}^{-1}}^{2}$} \\
\cline { 2 - 8 } & Value & Value & $\%$ & Value & $\%$ & Value & $\%$ \\
\hline Total Motility $(\%)$ & $7.40^{\mathrm{a}}$ & $6.69^{\mathrm{a}}$ & -9.63 & $12.17^{\mathrm{a}}$ & 64.43 & $11.02^{\mathrm{a}}$ & 48.86 \\
Progressive Motility $(\%)$ & $5.01^{\mathrm{ab}}$ & $3.15^{\mathrm{b}}$ & -37.19 & $5.31^{\mathrm{a}}$ & 5.99 & $4.42^{\mathrm{ab}}$ & -11.72 \\
VCL $(\mu \mathrm{m} / \mathrm{s})$ & $19.62^{\mathrm{b}}$ & $19.81^{\mathrm{b}}$ & 0.97 & $32.90^{\mathrm{ab}}$ & 67.69 & $50.43^{\mathrm{a}}$ & 157.03 \\
VSL $(\mu \mathrm{m} / \mathrm{s})$ & $10.20^{\mathrm{b}}$ & $12.12^{\mathrm{b}}$ & 18.82 & $21.10^{\mathrm{ab}}$ & 106.86 & $39.78^{\mathrm{a}}$ & 290.00 \\
VAP $(\mu \mathrm{m} / \mathrm{s})$ & $11.70^{\mathrm{b}}$ & $13.54^{\mathrm{b}}$ & 15.73 & $23.11^{\mathrm{ab}}$ & 97.52 & $42.03^{\mathrm{a}}$ & 259.23 \\
DCL $(\mu \mathrm{m})$ & $7.57^{\mathrm{a}}$ & $6.97^{\mathrm{a}}$ & -7.93 & $8.48^{\mathrm{a}}$ & 12.02 & $7.94^{\mathrm{a}}$ & 4.89 \\
DSL $(\mu \mathrm{m})$ & $3.63^{\mathrm{a}}$ & $3.84^{\mathrm{a}}$ & 5.79 & $4.06^{\mathrm{a}}$ & 11.85 & $3.83^{\mathrm{a}}$ & 5.51 \\
DAP $(\mu \mathrm{m})$ & $4.42^{\mathrm{a}}$ & $2.47^{\mathrm{a}}$ & -44.12 & $4.86^{\mathrm{a}}$ & 9.95 & $4.67^{\mathrm{a}}$ & 5.66 \\
ALH $(\mu \mathrm{m})$ & $0.35^{\mathrm{ab}}$ & $0.32^{\mathrm{b}}$ & -7.51 & $0.37^{\mathrm{a}}$ & 6.94 & $0.34^{\mathrm{b}}$ & -1.73 \\
BCF $(\mathrm{Hz})$ & $2.07^{\mathrm{ab}}$ & $1.53^{\mathrm{b}}$ & -26.09 & $2.43^{\mathrm{a}}$ & 17.39 & $1.79^{\mathrm{ab}}$ & -13.53 \\
WOB & $0.60^{\mathrm{b}}$ & $0.67^{\mathrm{ab}}$ & 11.11 & $0.71^{\mathrm{ab}}$ & 17.74 & $0.83^{\mathrm{a}}$ & 37.09 \\
LIN & $0.52^{\mathrm{b}}$ & $0.60^{\mathrm{ab}}$ & 15.29 & $0.64^{\mathrm{ab}}$ & 21.67 & $0.79^{\mathrm{a}}$ & 50.33 \\
STR & $0.87^{\mathrm{a}}$ & $0.90^{\mathrm{a}}$ & 3.84 & $0.89^{\mathrm{a}}$ & 2.69 & $0.95^{\mathrm{a}}$ & 9.61 \\
\hline
\end{tabular}

According to Tukey's test, equal letters along the lines represent non-significant variations between means $(P>0.05)$, while different letters represent significant variations $(P<0.05)$. The groups were evaluated between them and compared to the control group.

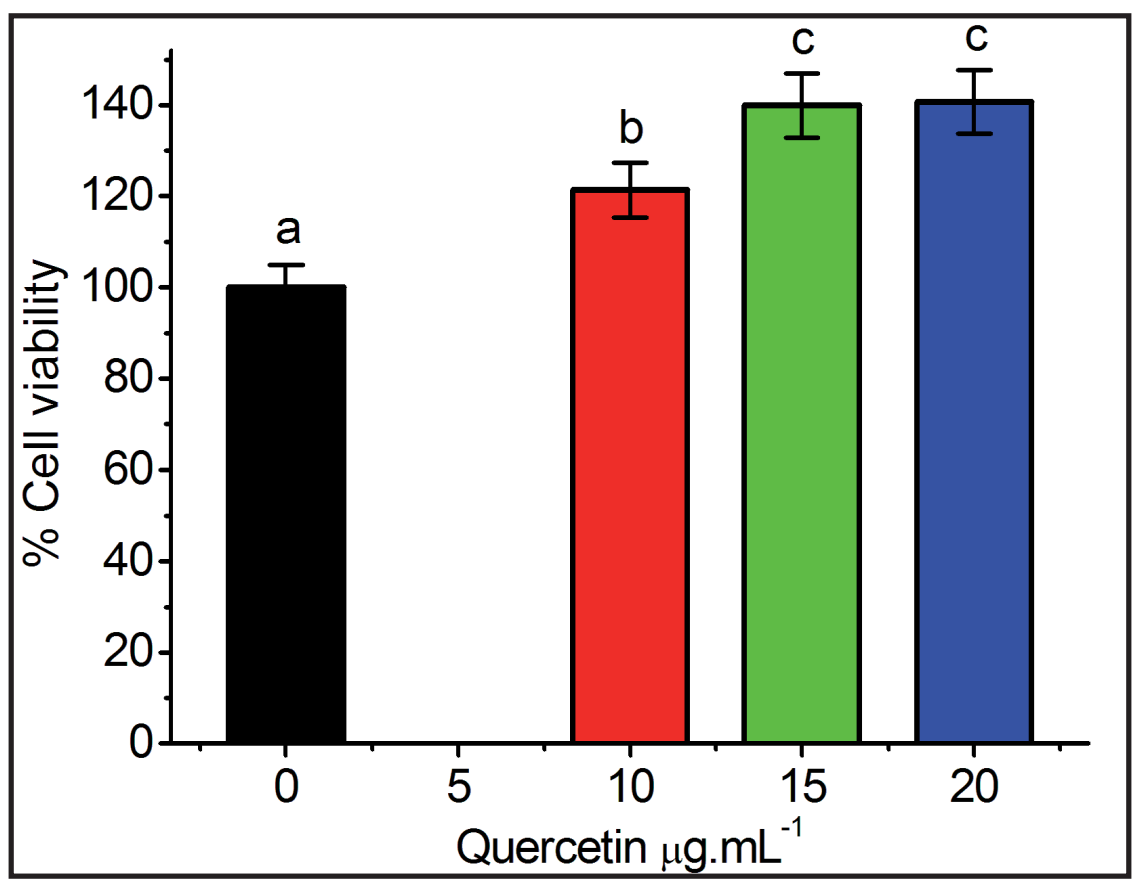

Figure 1. Metabolic activity assessed by the NBT test as a function of quercetin treatment. The percentage was evaluated by considering Metabolism of $100 \%$ control group $\left(0 \mu \mathrm{g} \cdot \mathrm{mL}^{-1}\right)$. Equal letters along the lines represent non-significant variations between means $(P>0.05)$, while different letters represent significant variations $(P<0.05)$. The groups were evaluated between them and compared to the control group. 


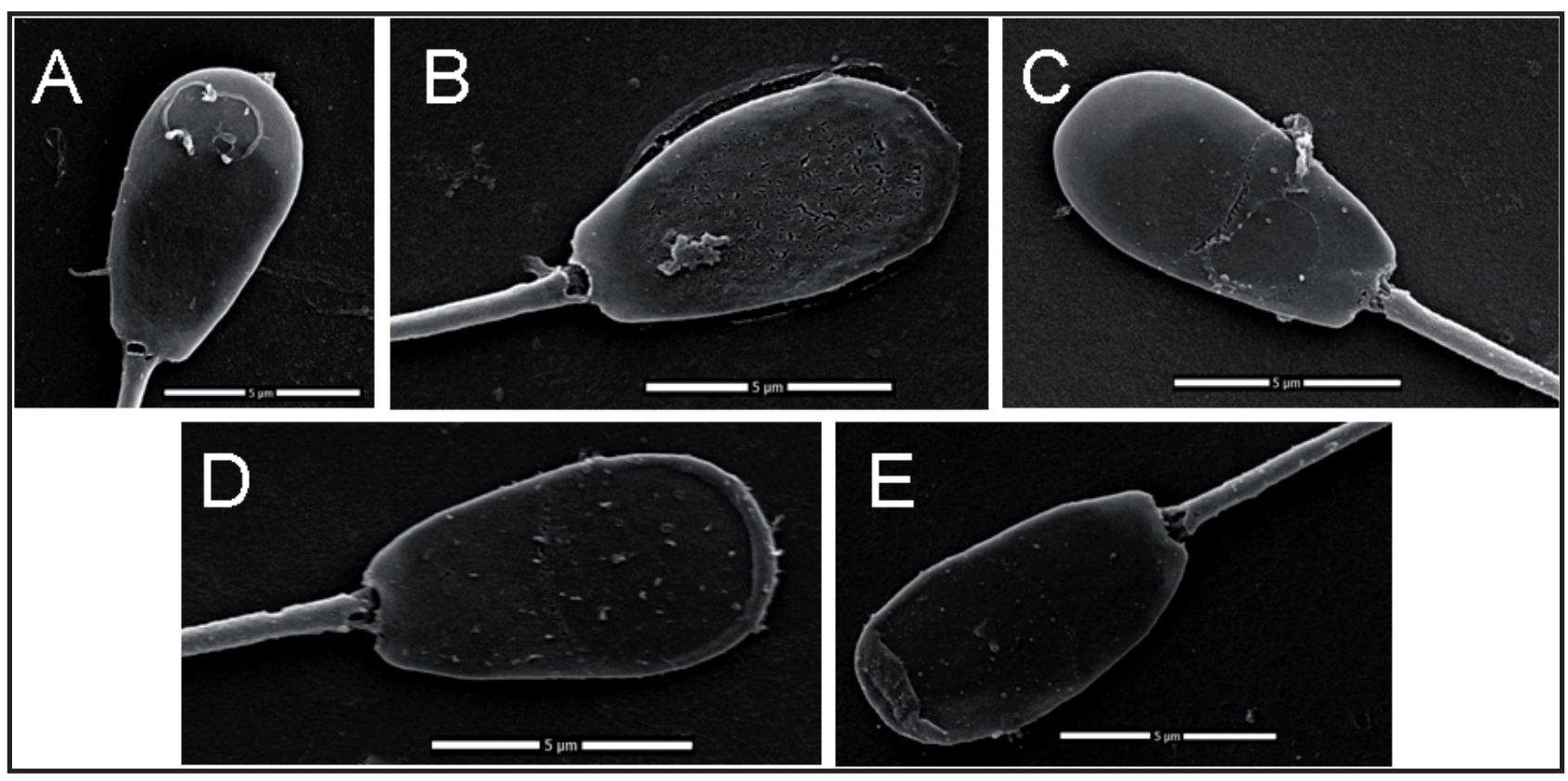

Figure 2. Photomicrography obtained by Scanning Eletronic Miscroscopy showing thawed bull spermatozoa previously treated with quercetin. Concentrations: A- 0 (Control); B- $5 \mu \mathrm{g} \cdot \mathrm{mL}^{-1}$; C- $10 \mu \mathrm{g} \cdot \mathrm{mL}^{-1}$; D- $15 \mu \mathrm{g} \cdot \mathrm{mL}^{-1} \& \mathrm{E}-20 \mu \mathrm{g} \cdot \mathrm{mL}^{-1}$. Magnification 25000x [Bars $\left.=5 \mu \mathrm{m}\right]$.

saturated fatty acids [14]. From the perspective of susceptibility to oxidative damage, the unsaturation of fatty acids is strongly affected by different mechanisms, and among them autoxidation is most likely to occur in spermatozoa.

The formation of free radicals is a phenomenon that is naturally observed in this fluid [3], and the reaction sequence of the autoxidation depend on the nature of the fatty acids present in membrane. Thus, it is expected that spermatozoa with a lipid membrane composition and a higher content of unsaturated than saturated fatty acids, as the bulls, are more sensitive to damage caused by freezing.

Freezing is not a natural phenomenon, and so evolutionary pressure did not operate to the point of selecting those whose semen is more resistant to the freezing process [4]. Considering the results presented here, we believe that antioxidant protection at the level of the mitochondrial membrane promoted the integrity of this organelle, and as a consequence a greater number of viable mitochondria was active. This promoted an observed increase in metabolic activity, which led to an increase in the velocity of spermatozoa treated with quercetin.

Scanning electron microscopy is widely used in spermatic examinations, and for the evaluation of the structural morphology of the cellular surface. In this sense, the most common morphological alteration in all of the samples was fragility and decapitation of spermatozoas. However, this type of damage had already been expected in thawed spermatozoa [12].
About spermatic quality, the literature reports that some of the CASA parameters provide a reliable estimation of the fertilizing ability of sperm, among them, the VCL might be important in sperm's fertilization abilities, being related to higher fertilization rates in vitro [13].

It is already well known that the addition of antioxidants agents to the sperm diluent may have some beneficial effect on the seminal parameters. In other work, the freeze-dried extract of Albizia harveyi, which contained 35 phenolic compounds, among them quercetin and quercetin derivatives was supplemented to the tris-yolk fructose extender and added to the pooled bull semen, as we did in this work. As a result, the extract increased the percentage of viable sperm cells in the same proportion as we observed here [21].

\section{CONCLUSION}

Treatment with quercetin was able to improve velocities (VCL, VSL, VAP) and as a consequence, wobble and linearity in bull sperm with quercetin concentration of $20 \mu \mathrm{g} \cdot \mathrm{mL}^{-1}$.

Furthermore, the addition of quercetin to the sperm diluent prior to freezing allowed the spermatozoa to maintain a higher metabolic rate after thawing, of approximately $40 \%$ using $15 \mu \mathrm{g} \cdot \mathrm{mL}^{-1}$ quercetin, which result in faster spermatozoa. Therefore, it is concluded that supplementation of quercetin in exten- 
der was able to promote beneficial effects to bovine semen, resulting in possible higher rates of fertilization.

\section{MANUFACTURERS}

${ }^{1}$ Sigma-Aldrich. St. Louis, MO, USA.

${ }^{2}$ LabSynth Produtos para Laboratórios Ltda. Diadema, SP, Brazil.

${ }^{3}$ Merck Brasil. São Paulo, SP, Brazil.

${ }^{4}$ Shimadzu Corporation. Shinagawa, Tokyo, Japan.

${ }^{5}$ Minitube do Brasil, Porto Alegre, RS, Brazil.

Acknowledgements. This study was funded by Fundação
Araucária (grants 147/14 and 40/16), FINEP, CAPES and COMCAP/UEM.

Ethical approval. All experimental procedures were performed under the supervision of the Ethics Committee of the State University of Maringá, according to ethical principles and animal welfare.

Declaration of interest. The authors report no conflicts of interest. The authors alone are responsible for the content and writing of the paper.

\section{REFERENCES}

1 Aitken R.J., Lambourne S. \& Gibb Z. 2014. The John Hughes Memorial Lecture: aspects of sperm physiologyoxidative stress and the functionality of stallion spermatozoa. Journal of Equine Veterinary Science. 34: 17-27. DOI: 10.1016/j.jevs.2013.10.120

2 Colégio Brasileiro de Reprodução Animal. 2013. Manual para exame andrológico e avaliação de sêmen animal. 3.ed. Belo Horizonte: Colégio Brasileiro de Reprodução Animal, 104p.

3 Chatterjee S. \& Gagnon C. 2001. Production of reactive oxygen species by spermatozoa undergoing cooling, freezing, and thawing. Molecular Reproduction and Development: Incorporating Gamete Research. 59: 451-458. DOI: $10.1002 / \mathrm{mrd} .1052$

4 Condessa M.A.K.V., Pimentel A.L., Seixas F.A.V. \& Martinez A.C. 2018. Purification, structural and biophysical characterisation of the major seminal plasma protein from Texel rams. Animal Reproduction Science. 189: 11-18. DOI: 10.1016/j.anireprosci.2017.10.013

5 Da Silva J.M.R., Darmon N., Fernandez Y. \& Mitjavila S. 1991. Oxygen free radical scavenger capacity in aqueous models of different procyanidins from grape seeds. Journal of Agricultural and Food Chemistry. 39: 1549-1552. DOI: $10.1021 /$ jf00009a002

6 Davies K.J. 1987. Protein damage and degradation by oxygen radicals. I. general aspects. Journal of Biological Chemistry. 262: 9895-9901. PMID: 3036875

7 Dean R.T., Hunt J.V., Grant A.J., Yamamoto Y. \& Niki E. 1991. Free radical damage to proteins: the influence of the relative localization of radical generation, antioxidants, and target proteins. Free Radical Biology and Medicine. 11: 161-168. PMID: 1937134

8 Dedavid B.A., Gomes C.I. \& Machado G. 2007. Microscopia eletrônica de varredura: aplicações e preparação de amostras: materiais poliméricos, metálicos e semicondutores. Porto Alegre: EdiPUCRS, 6p.

9 Gibb Z., Butler T., Morris L. Maxwell W. \& Grupen C. 2013. Quercetin improves the postthaw characteristics of cryopreserved sex-sorted and nonsorted stallion sperm. Theriogenology. 79: 1001-1009. DOI: 10.1016/j.theriogenology.2012.06.032

10 Grimstone A.V. 1980. O Microscópio Eletrônico em Biologia. São Paulo: EPU/EDUSP, 70p.

11 Hafez E.S.E. \& Hafez B. 2004. Reprodução animal. 7.ed. São Paulo: Manole, 513p.

12 Hammadeh M.E., Askari A.S., Georg T., Rosenbaum P. \& Schmidt W. 1999. Effect of freeze-thawing procedure on chromatin stability, morphological alteration and membrane integrity of human spermatozoa in fertile and subfertile men. International Journal of Andrology. 22: 155-162. PMID: 10367235

13 Hirano Y., Shibahara H., Obara H., Suzuki T., Takamizawa S. \& Yamaguchi C. 2001. Andrology: Relationships Between Sperm Motility Characteristics Assessed by the Computer-Aided Sperm Analysis (CASA) and Fertilization Rates In Vitro. Journal of Assisted Reproduction and Genetics. 18: 215-220. DOI: 10.1023/A:1009420432234

14 Holt W.V. 2000. Basic aspects of frozen storage of semen. Animal Reproduction Science. 62: 3-22. PMID: 10924818

15 Jain N.C. 1986. Schalm's Veterinary Hematology. Philadelphia: Lea \& Febiger, 1221p.

16 Kaneko J.J., Harvey J.W. \& Bruss M.L. 2008. Clinical biochemistry of domestic animals. 6th edn. Burlington: Academic Press, 928p.

17 Liu S., Hou W., Yao P., Zhang B., Sun S. \& Nüssler A.K. 2010. Quercetin protects against ethanol-induced oxidative damage in rat primary hepatocytes. Toxicology in Vitro. 24: 516-522. DOI: 10.1016/j.tiv.2009.03.006 
18 Nakagawa K., Kawagoe M., Yoshimura M., Arata H., Minamikawa T. \& Nakamura M. 2000. Differential effects of flavonoid quercetin on oxidative damages induced by hydrophilic and lipophilic radical generators in hepatic lysosomal fractions of mice. Journal of Health Science. 46: 509-512. DOI: 10.1248/jhs.46.509

19 Saalu L. 2010. The incriminating role of reactive oxygen species in idiopathic male infertility: an evidence based evaluation. Pakistan Journal of Biological Science. 13: 413.

20 Silva E., Cajueiro J., Silva S., Soares P. \& Guerra M. 2012. Effect of antioxidants resveratrol and quercetin on in vitro evaluation of frozen ram sperm. Theriogenology. 77: 1722-1726. DOI: 10.1016/j.theriogenology.2011.11.023

21 Sobeh M., Hassan S.A., El Raey M.A., Khalil W.A., Hassan M.A.E. \& Wink M. 2017. Polyphenolics from Albizia harveyi exhibit antioxidant activities and counteract oxidative damage and ultra-structural changes of cryopreserved bull semen. Molecules. 22(11). DOI: 10.3390/molecules22111993

22 Tvrdá E., Kováčik A., Tušimová E., MassányI P. \& Lukáč N. 2015. Resveratrol offers protection to oxidative stress induced by ferrous ascorbate in bovine spermatozoa. Journal of Environmental Science and Health. Part C. 50: 14401451. DOI: $10.1080 / 10934529.2015 .1071153$

23 Verstegen J., Iguer-Ouada M. \& Onclin K. 2002. Computer assisted semen analyzers in andrology research and veterinary practice. Theriogenology. 57: 149-179.

24 Watson P. 2000. The causes of reduced fertility with cryopreserved semen. Animal Reproduction Science. 60: 481-92.

25 Zribi N., Chakroun N.F., Abdallah F.B., Elleuch H., Sellami A. \& Gargouri J. 2012. Effect of freezing-thawing process and quercetin on human sperm survival and DNA integrity. Cryobiology. 65: 326-331. 